\title{
Premenstrual Symptoms and Posttraumatic Stress Disorder in Japanese High School Students 9 Months after the Great East-Japan Earthquake
}

\author{
Takashi Takeda, ${ }^{1,2}$ Mari Tadakawa, ${ }^{2}$ Shoko Koga ${ }^{3}$ Satoru Nagase $^{2}$ and \\ Nobuo Yaegashi ${ }^{2}$ \\ ${ }^{1}$ Division of Women's Health, Research Institute of Traditional Asian Medicine, Kinki University School of \\ Medicine, Osaka-Sayama, Osaka, Japan \\ ${ }^{2}$ Department of Obstetrics and Gynecology, Tohoku University Graduate School of Medicine, Sendai, Miyagi, \\ Japan \\ ${ }^{3}$ Gynecology Clinic Koga, Sendai, Miyagi, Japan
}

On March 11, 2011, the Great East-Japan Earthquake occurred and a massive tsunami hit the northeastern coast of Japan. Catastrophic disasters such as earthquakes and war cause tremendous damage, not only physically but also mentally. Posttraumatic stress disorder (PTSD) is an anxiety disorder that occurs in the aftermath of a traumatic event. Premenstrual syndrome (PMS) is a cluster of psychological and somatic symptoms that are limited to the late luteal phase of the menstrual cycle. Premenstrual dysphoric disorder (PMDD) is considered a severe form of PMS. To determine the relationship between premenstrual symptoms and natural disaster-induced PTSD among Japanese adolescent girls, we conducted a crosssectional study. Overall, 1489 high school students who belong to two high schools in Sendai, the largest city in northeastern Japan, were assessed 9 months after the earthquake. These schools are located inland, far from the seashore, and were not damaged by the tsunami. Premenstrual symptoms were assessed using the Premenstrual Symptoms Questionnaire, and PTSD symptoms were assessed using the Japanese-language version of Impact of Event Scale-Revised, which is a widely used self-assessment questionnaire about PTSD symptoms. We analyzed the data of 1,180 girls who completed the questionnaires and 118 girls (10.0\%) were classified as having PTSD. The prevalence rates of PMDD and moderate to severe PMS increased according to the comorbidity of PTSD $(p<0.001)$, showing a correlation between the severity of PMS/PMDD and natural disaster-induced PTSD. The comorbidity of PMS/PMDD and PTSD may complicate the follow-up of both conditions.

Keywords: Great East-Japan Earthquake; high school students; posttraumatic stress disorder; premenstrual dysphoric disorder; premenstrual syndrome

Tohoku J. Exp. Med., 2013 July, 230 (3), 151-154. (C) 2013 Tohoku University Medical Press

\section{Introduction}

On March 11, 2011, the Great East-Japan Earthquake occurred and a massive tsunami hit the northeastern coast of Japan. Catastrophic disasters such as earthquakes and war cause tremendous damage, not only physically but also mentally. Posttraumatic stress disorder (PTSD) is an anxiety disorder that occurs in the aftermath of a traumatic event. In general, women are more sensitive to traumatic events than men and are more likely to be affected by PTSD (Yehuda 2002).

Premenstrual syndrome (PMS) is a constellation of mood, behavioral, and physical symptoms that are limited to the late luteal phase of the menstrual cycle (Yonkers et al. 2008). Premenstrual dysphoric disorder (PMDD) is a severe form of PMS. The Diagnostic and Statistical Manual of Mental Disorders (DSM-IV; American Psychiatric Association 1994) describes research criteria for PMDD. The causes of PMS and PMDD have been suggested to include hormonal changes, neurotransmitters, diet, stress, and lifestyle (Grady-Weliky 2003). Adolescence is an important and vulnerable period between childhood and adulthood. Previously we have reported that PMS and PMDD are common menstrual problems in adolescents and should be treated as carefully as dysmenorrhea (Takeda et al. 2010).

Several epidemiological studies have demonstrated the associations between PMDD and PTSD (Wittchen et al.

Received April 19, 2013; revised and accepted June 25, 2013. Published online July 9, 2013; doi: 10.1620/tjem.230.151.

Correspondence: Takashi Takeda, Division of Women's Health, Research Institute of Traditional Asian Medicine, Kinki University

School of Medicine, 377-2, Ohno-Higashi, Osaka-Sayama, Osaka 589-8511, Japan.

e-mail: take@med.kindai.ac.jp 
2003; Perkonigg et al. 2004; Pilver et al. 2011), but there is no report about the relationship between PMS/PMDD and natural disaster-induced PTSD. Our aim is to examine whether there is a relationship between the severity of PMS/PMDD and PTSD in adolescent girls.

\section{Methods}

The study was carried out in accordance with the principles outlined in the Declaration of Helsinki. The institutional review board at Tohoku University approved the study.

\section{Study population}

A school-based survey was conducted in December 2011 using a sample of Japanese female students who belong to two public high schools in Sendai, the largest city in northeastern Japan. These schools are located inland and were not damaged by the tsunami. We have been conducting this survey annually since 2009 to assess the prevalence and impact of premenstrual symptoms among Japanese adolescent girls attending these schools (Takeda et al. 2010; Kitamura et al. 2012). We recruited female high school students who had regular menstrual cycles (22-35 days) and were able to provide informed consent.

\section{Questionnaire}

We used the Premenstrual Symptoms Questionnaire (PSQ), which was developed in our previous study (Takeda et al. 2006), to screen for premenstrual symptoms. The PSQ translates DSM-IV criteria into a rating scale with degrees of severity described in Japanese and is essentially identical to the Premenstrual Symptoms Screening Tool (Steiner et al. 2003). We divided girls with premenstrual symptoms into three groups: 'PMDD', 'moderate to severe PMS', and 'no/ mild PMS' according to the criteria reported previously (Steiner et al. 2003; Takeda et al. 2006). PTSD symptoms were assessed using the Japanese-language version of Impact of Event Scale-Revised (IES-R) (Asukai et al. 2002). A 24/25 cut-off in total score was set to determine PTSD.
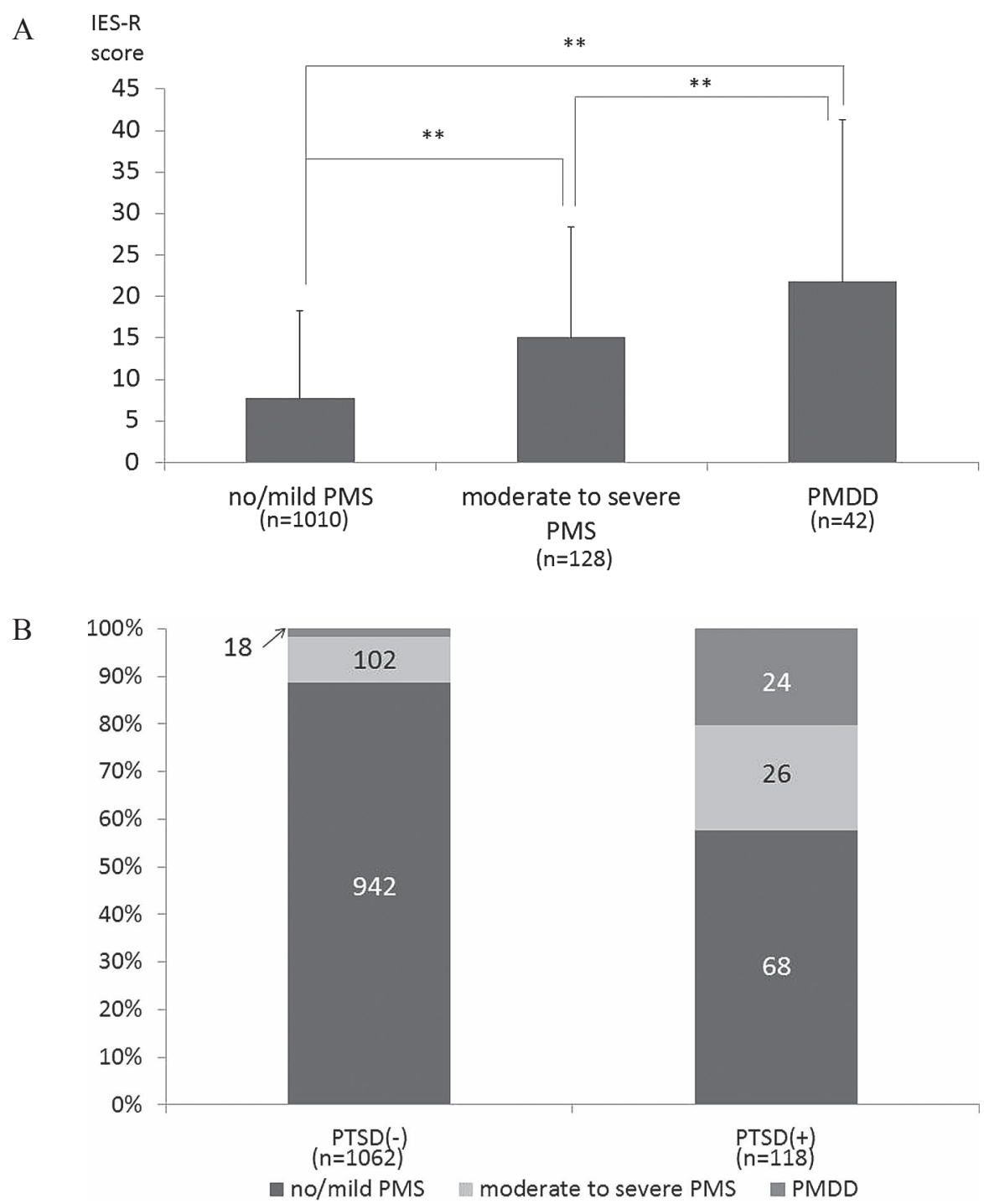

Fig. 1. Relationship between severity of PMS and PTSD. (A) IES-R score and severity of PMS. Bars, mean \pm S.D. ${ }^{* *} p<$ 0.01. (B) Prevalence of PTSD and PMS/PMDD. 


\section{Results}

A total of 1350 female students completed the questionnaire. One hundred seventy were excluded from the analysis because of incomplete data; therefore, we analyzed the data of 1180 girls aged 15 to 18 years (average $16.7 \pm$ 0.89 (s.D.) years).

The 'PMDD' group consisted of 42 girls (3.6\%); the 'moderate to severe PMS' group, 128 girls (10.8\%); and the 'no/mild PMS' group, 1,010 girls (85.6\%). The average IES-R score significantly increased according to the severity of PMS symptoms ( $p<0.01$ by one-way ANOVA followed by Scheffe's F test) (Fig. 1A). One hundred eighteen girls $(10.0 \%)$ scored $\geq 25$ points and were classified as having PTSD. The prevalence rates of 'PMDD' and 'moderate to severe PMS' increased according to the comorbidity of PTSD ( $p<0.001$ by Mann-Whitney's $U$ test) (Fig. 1B).

Next we compared the differences between the two schools. As shown in Table 1, the severity of PMS and PTSD in School B was significantly higher than in School A. During these three years, the rates of PMDD and moderate to severe PMS in School A did not change, but significantly changed in School B (Table 2).

\section{Discussion}

To our knowledge, this is the first study to refer to the relationship between the severity of PMS/PMDD and natural disaster-induced PTSD. The association between PTSD and PMDD has been explicitly examined by German and American studies (Wittchen et al. 2003; Perkonigg et al. 2004; Pilver et al. 2011). The German prospective longitudinal community survey showed that, compared to nonPMDD women, PMDD women were more likely to have experienced physical threat, sexual abuse during childhood and severe accidents. The greatest difference between these studies and our study is that the former examined all traumatic event types, while the latter deals with only the trauma induced by the Great East-Japan Earthquake.

Surprisingly, our data showed a significant difference in the severity of PTSD and PMS/PMDD between the two schools. The schools are located within $2 \mathrm{~km}$ of each other in almost the same area of Sendai city. Before the survey, we confirmed that no students had been victims of the earthquake and that their classes had returned to normal. A likely explanation for this difference is that the commuting area of School B is wider than School A. The majority of students live inland, but the percentage of students who live in the coastal area is much higher in School B than School A. For example, only four students in School A (0.005\%) live in Ishinomaki city, the worst-hit coastal area, while 25 in School B (3.5\%).

What causes the correlation between PMS/PMDD and

Table 1. Severity of PMS/PMDD and PTSD by school.

\begin{tabular}{lccc}
\hline & A $(n=561)$ & B $(n=619)$ & $P$ value \\
\hline PMS/PMDD (\%) & $499(89)$ & $511(82.6)$ & 0.001 \\
no/mild PMS & $50(8.9)$ & $78(12.6)$ & (Mann-Whitney's $U$-test) \\
moderate to severe PMS & $12(2.1)$ & $30(4.9)$ & $<0.001$ \\
PMDD & $5.27(8.0)$ & $12.5(13.5)$ & (Student's $t$-test) \\
\hline IES-R score (s.D.) & $544(97)$ & $518(83.7)$ & $<0.001$ \\
\hline PTSD (\%) - & $17(3.0)$ & $101(16.3)$ & (Chi-square test) \\
\hline
\end{tabular}

Table 2. Rates of PMS/PMDD across the 3-years.

\begin{tabular}{|c|c|c|c|c|c|}
\hline & & $\begin{array}{c}\text { no/mild PMS } \\
(\%)\end{array}$ & $\begin{array}{c}\text { moderate to } \\
\text { severe PMS (\%) }\end{array}$ & PMDD (\%) & $P$ value \\
\hline \multirow[t]{3}{*}{ (Total) } & 2011 & $1,010(85.6)$ & $128(10.8)$ & $42(3.56)$ & \multirow{3}{*}{$\begin{array}{c}0.194 \\
\text { (Kruskal-Wallis test) }\end{array}$} \\
\hline & 2010 & $1,167(88.1)$ & $116(8.75)$ & $42(3.17)$ & \\
\hline & 2009 & $1,176(86.8)$ & $138(10.2)$ & $41(3.03)$ & \\
\hline \multirow[t]{3}{*}{ (A) } & 2011 & 499 (88.9) & $50(8.91)$ & $12(2.14)$ & \multirow{3}{*}{$\begin{array}{c}0.213 \\
\text { (Kruska1-Wallis test) }\end{array}$} \\
\hline & 2010 & $530(86.5)$ & $62(10.1)$ & $21(3.43)$ & \\
\hline & 2009 & $529(85.6)$ & 73 (11.8) & $16(2.59)$ & \\
\hline \multirow[t]{3}{*}{ (B) } & 2011 & $511(82.6)$ & 78 (12.7) & $30(4.85)$ & \multirow{3}{*}{$\begin{array}{c}<0.001 \\
(\text { Kruska1-Wallis test })\end{array}$} \\
\hline & 2010 & $637(89.5)$ & $54(7.58)$ & $21(2.95)$ & \\
\hline & 2009 & $647(87.8)$ & $65(8.82)$ & $25(3.39)$ & \\
\hline
\end{tabular}


PTSD is unknown, but we can suggest a possible explanation. PMS/PMDD and PTSD may have overlapping biochemical etiologies, including the possible role of the serotonergic system in both. Further investigation is needed to clarify why PMS/PMDD and PTSD have a positive correlation.

The findings of our study have important implications for clinicians. First, when we treat an adolescent girl presenting with PTSD symptoms, we must always be aware of PMS/PMDD. Second, clinicians should follow their patients' symptoms in relation to their menstrual cycle. The comorbidity of PMS/PMDD and PTSD may complicate the follow-up of both conditions. Finally, we should note that 9 months after the earthquake, the incidence of PTSD was still high among female high school students in earthquake areas without severe property damage. It has been reported that PTSD is associated with a low-grade systemic proinflammatory state, which could contribute to atherosclerosis (von Känel et al. 2007). Moreover, PTSD in adolescents has been suggested to be associated with the objective disease states, such as circulatory disease (Seng et al. 2005). Clinicians should care for girls in disaster areas both mentally and physically now and in the future.

\section{Conflict of Interest}

The authors declare that they have no conflicts of interest.

\section{References}

American Psychiatric Association (1994) Diagnostic and statistical manual of mental disorders, fourth edition (DSM-IV). American Psychiatric Press, Washington, DC, pp. 715-718.

Asukai, N., Kato, H., Kawamura, N., Kim, Y., Yamamoto, K., Kishimoto, J., Miyake, Y. \& Nishizono-Maher, A. (2002) Reliability and validity of the Japanese-language version of the impact of event scale-revised (IES-R-J): four studies of different traumatic events. J. Nerv. Ment. Dis., 190, 175-182. Grady-Weliky, T.A. (2003) Clinical practice. Premenstrual dysphoric disorder. N. Engl. J. Med., 348, 433-438.

Kitamura, M., Takeda, T., Koga, S., Nagase, S. \& Yaegashi, N. (2012) Relationship between premenstrual symptoms and dysmenorrhea in Japanese high school students. Arch. Womens Ment. Health, 15, 131-133.

Perkonigg, A., Yonkers, K.A., Pfister, H., Lieb, R. \& Wittchen, H.U. (2004) Risk factors for premenstrual dysphoric disorder in a community sample of young women: the role of traumatic events and posttraumatic stress disorder. J. Clin. Psychiatry, 65, 1314-1322.

Pilver, C.E., Levy, B.R., Libby, D.J. \& Desai, R.A. (2011) Posttraumatic stress disorder and trauma characteristics are correlates of premenstrual dysphoric disorder. Arch. Womens Ment. Health, 14, 383-393.

Seng, J.S., Graham-Bermann, S.A., Clark, M.K., McCarthy, A.M. \& Ronis, D.L. (2005) Posttraumatic stress disorder and physical comorbidity among female children and adolescents: results from service-use data. Pediatrics, 116, e767-776.

Steiner, M., Macdougall, M. \& Brown, E. (2003) The premenstrual symptoms screening tool (PSST) for clinicians. Arch. Womens Ment. Health, 6, 203-209.

Takeda, T., Koga, S. \& Yaegashi, N. (2010) Prevalence of premenstrual syndrome and premenstrual dysphoric order in Japanese high school students. Arch. Womens Ment. Health, 13, 535537.

Takeda, T., Tasaka, K., Sakata, M. \& Murata, Y. (2006) Prevalence of premenstrual syndrome and premenstrual dysphoric disorder in Japanese women. Arch. Womens Ment. Health, 9, 209-212.

von Känel, R., Hepp, U., Kraemer, B., Traber, R., Keel, M., Mica, L. \& Schnyder, U. (2007) Evidence for low-grade systemic proinflammatory activity in patients with posttraumatic stress disorder. J. Psychiatr. Res., 41, 744-752.

Wittchen, H.U., Perkonigg, A. \& Pfister, H. (2003) Trauma and PTSD - an overlooked pathogenic pathway for premenstrual dysphoric disorder? Arch. Womens Ment. Health, 6, 293-297.

Yehuda, R. (2002) Post-traumatic stress disorder. N. Engl. J. Med., 346, 108-114.

Yonkers, K.A., O’Brien, P.M. \& Eriksson, E. (2008) Premenstrual syndrome. Lancet, 371, 1200-1210. 